\title{
Educación en el hogar en Chile. Informe de resultados de la Encuesta Nacional
}

\author{
LESTER ALIAGA CASTILLO" \\ Centro Educacional de Alta Tecnología \\ y Universidad San Sebastián de Concepción, Chile \\ Recibido el 20-11-2015; primera evaluación el 25-07-2016; segunda \\ evaluación el 09-10--2016; tercera evaluación el 30-10-2016; cuarta \\ evaluación el 31-10-2016; aceptado el 01-11-2016
}

\section{RESUMEN}

En 2014 se realizó una encuesta para levantar información acerca de las familias que practican el homeschooling en Chile. Respondieron 67 familias acerca de los motivos que tuvieron, los valores que les interesa, sus formas de socialización, las fuentes para desarrollar el currículum y la gestión del tiempo para el aprendizaje. Este trabajo forma parte de una investigación mayor acerca de la educación en el hogar en Chile.

Palabras clave: educación en el hogar, valores, validación de estudios, socialización, tiempo dedicado.

\section{Homeschooling in Chile. Report National Survey Results}

\section{Abstract}

In 2014 a survey to gather information about families who practice homeschooling in Chile took place. They answered 67 families on the reasons that took the values they care, forms of socialization, the sources to develop the curriculum and time management for learning. This work is part of a larger research on home education in Chile.

Keywords: home education, values, validation studies, socialization, dedicated time.

\footnotetext{
* Profesor de Español, magíster en Administración Educacional y máster en Innovación Educativa. En la actualidad redacta su tesis de doctorado por la Universidad de Alcalá, España. Vive en San Pedro de la Paz, provincia de Concepción, Chile y, aparte de su labor docente, mantiene un programa de literatura en la Radioemisora de la Universidad de Concepción. Contacto: lesteraliaga@ceat.cl, laliaga@ceat.cl
} 


\section{Homeschooling no Chile. Relatório de resultados da Pesquisa Nacional}

\section{Resumo}

Em 2014 uma pesquisa para coletar informaçôes sobre as famílias que praticam Homeschooling no Chile ocorreu. Eles responderam a 67 famílias sobre os motivos que levaram os valores que lhes interessam, formas de socialização, as fontes para desenvolver o currículo e gerenciamento de tempo para a aprendizagem.

Este trabalho é parte de uma pesquisa maior sobre a educaçáo em casa no Chile.

Palavras-chave: início educação, valores e estudos de validação, a socializaçáo, o tempo dedicado.

\section{INTRODUCCIÓN}

En el último tiempo, familias chilenas han optado por una alternativa educacional que significa desescolarizar a sus hijos, educarlos al margen del sistema escolar, sin asistir a una escuela o colegio. Esta opción es más radical que otras alternativas que tampoco consideran el currículum nacional y no se someten a la normativa oficial, principalmente colegios que implementan las pedagogías Montessori o Waldorf (Céspedes, 2014) que por lo general son instituciones privadas en las que se debe cancelar una mensualidad, regularmente alta.

A esta alternativa desescolarizadora, Julio Lagos (2012, p. 432) la define como: «el resultado de la preferencia de los padres para eludir la escuela institucional y educar a sus propios niños, es decir, para ejercer su papel de educadores directamente y no a través del vehículo del ambiente escolar tradicional».

\section{Planteamiento del problema}

Se aprecia un creciente interés de familias, que viven en diferentes regiones del país, por la educación en casa, opción que implica no matricular a los hijos/as en las escuelas, colegios y liceos del sistema formal que rige el Ministerio de Educación de Chile.

Este trabajo de investigación, a partir de la aplicación de una encuesta nacional, pretende aportar información especialmente cualitativa y reflexionar acerca de los datos obtenidos para comenzar a comprender el fenómeno.

\section{ANTECEDENTES}

La educación en casa es la forma más antigua de educación y su efectividad ha sido probada durante siglos. El sistema escolarizado que conocemos surgió a 
raíz de las necesidades de disponer de trabajadores que requería la revolución industrial. Se basa sobre dos pilares que se han mantenido por los dos siglos apenas que tiene de existencia:

1. Las materias deben ser útiles para el mundo del trabajo.

2. Se desarrollan principalmente habilidades académicas.

La educación en casa comenzó a partir de la década de 1970 en Estados Unidos como, en el caso de comunidades religiosas, un deseo de retornar al diseño divino en la educación de los hijos y, por otro lado, frente a la sensación de que el sistema escolarizado no satisfacía las necesidades de desarrollo en libertad y con creatividad.

Gran parte de sus inspiradores son autores de las décadas de 1960 y 1970 que cuestionan la educación convencional y plantean un paradigma distinto. En Aliaga (2013) se destaca que el movimiento desescolarizador: «llamaba a eliminar el sistema escolar, principalmente por estar al servicio de los intereses y valores de la sociedad capitalista, según sus principales impulsores: Paul Goodman, Iván Illich y Everett Reimer» (p. 2).

Murphy (2012, p. 10) afirma que: «El crecimiento de la educación en casa en Estados Unidos [donde es legal, pero su regulación depende de cada Estado] ha sido nada menos que notable, incluso utilizando las estimaciones más conservadoras disponibles...[de] 10.000-15.000 niños... en 1970... [a] alrededor de 2 millones de estudiantes [en 2010]».

El sitio de Universia-Argentina (2015), en su sección de Noticias, informaba en abril de este año: «Según el National Center for Education Statistics, en Estados Unidos, el número de homeschoolers creció 74\%: pasó de 850.000 en 1999 a 1,5 millones en 2007, actualmente se estima que son más de 2 millones...».

A mediados de 2015 se publicó la última edición del Informe del Instituto Fraser (2015), con los principales aportes y actualización de datos del Centro Barbara Mitchell para el Mejoramiento de la educación. El instituto, con sede en Canadá, país que tiene 40 años de experiencia en este tipo de educación, informa que una cantidad cada vez más importante de familias está optando por la educación en casa, dando cuenta de la última cifra oficial, correspondiente al año 2012, de 21662 niños y jóvenes que se educan en casa en Canadá.

En la mayoría de los países de Europa es legal (Escriu, 2015), excepto en España, Grecia, Alemania y los Países Bajos, lo que no impide que de todas formas haya familias dispuestas a enfrentar a los tribunales de justicia para

1 Traducción propia del original en inglés. 
hacer efectiva su objeción de conciencia y cumplir con el deseo de educar a sus hijos/as en el hogar.

En América Latina, en tanto, no está expresamente prohibida, salvo en Brasil, Cuba, El Salvador y Guatemala. En el caso de Chile, el artículo 19 de la Constitución Política (2012) asegura a todas las personas, en el numeral 10, el derecho a la educación y en el inciso segundo se lee: «Los padres tienen el derecho preferente y el deber de educar a sus hijos».

Son pocas las investigaciones que se han hecho hasta ahora. Para algunos investigadores, todavía es un fenómeno minoritario.

El año 2013 se realizó en Santiago el Primer Congreso Nacional de Homeschooling. En esa ocasión participaron más de trescientas personas interesadas en el tema, la mayoría familias que ya realizaban la educación en el hogar. En 2014 se repitió la experiencia y en 2015 se realizó el Tercer Congreso, con un aumento notable de redes de apoyo, grupos en redes sociales, especialmente Facebook, y organizaciones como Homeschool Consagrado al Seńor, que ha desarrollado toda una estrategia de apoyo con líderes y grupos para cada año de enseñanza.

En esta investigación utilizaremos la expresión educación en el hogar, por la carga emotiva que le asignamos a la palabra «hogar».

En Chile, no hay trabas legales para ejercerla, sí algunos prejuicios y la ignorancia o desatención de muchos, incluso de funcionarios que deben responder consultas al respecto.

\section{Encuesta Nacional de Educación en el Hogar}

La idea de hacer una encuesta nacional surgió durante la realización del Primer Congreso Nacional de Homeschooling de Chile. En ese encuentro, se verificó una gran diversidad geográfica, grupal y religiosa, por lo que se decidió realizar una consulta a través de los mismos sitios de internet que convocaron al Congreso, con las autorizaciones respectivas.

3.1. Confección de la encuesta. La Encuesta Nacional de Homeschooling se organizó entre diciembre de 2013 y marzo de 2014. En ese período se revisaron dos encuestas anteriores realizadas por las líderes de los dos sitios chilenos más importantes: Cristina Matus, de Educo Chile, y Koreen Mazurek, de Homeschool Consagrado al Señor. La orientación de las encuestas mencionadas era distinta de la que desarrolla esta investigación, pero había información que podíamos utilizar en la triangulación y en la eventual confección de un mapa de la educación en el hogar en Chile. En diciembre de 2014 se procedió 
a confeccionar la parrilla de preguntas, teniendo presentes los objetivos de esta investigación:

1. Identificar los motivos, valores y el currículum que desarrollan quienes se educan en el hogar.

2. Analizar las instancias de sociabilización que tienen quienes estudian en el hogar.

3. Estudiar la gestión del tiempo dedicado a la educación en el hogar.

3.2. Validación de la encuesta. En el período enero-febrero de 2014 la encuesta original de 38 preguntas fue sometida a juicio de expertos. Después de discutir algunos alcances, se redactó la forma definitiva de la encuesta y se solicitó autorización a dos sitios de Facebook para publicar el enlace con la encuesta confeccionada, utilizando la herramienta Formulario de Google Drive: Educo Chile y Homeschool Consagrado al Señor. Estas instituciones apoyaron, además, con un correo desde sus propias organizaciones para que las familias respondieran la encuesta con confianza.

3.3. De la población y la muestra. La unidad de análisis son las familias que realizan educación en el hogar en Chile. Al delimitar el universo o población por estudiar se consideró la siguiente especificación: familias que realizan educación en el hogar en Chile, participantes de los sitios de Facebook: Educo Chile y Homeschool Consagrado al Señor.

La población a julio de 2014 era de 550 personas que respondían por sus correspondientes familias. En tanto, la muestra la constituyeron 67 encuestas respondidas entre el 11 de marzo y el 25 de julio de 2014 por 57 madres y 10 padres.

3.4. De la recepción de encuestas. El 11 de marzo de 2014 se publicó el enlace de la encuesta y comenzó la recepción en el Drive, opción Formularios, del correo electrónico del investigador, hasta el 25 de julio.

\section{Resultados}

\subsection{Información de las madres}

4.1.1. Edad y procedencia. La edad de las madres va de los 24 a los 48 años, siendo el segmento entre 30 y 39 años el intervalo que contiene más madres (37 madres), ubicándose la moda en los 34 ańos. Las madres provienen de diferentes lugares de Chile, aunque hay ocho que nacieron en otros países: dos en EE.UU, dos en Argentina y una en Perú, Bolivia, Ecuador e Inglaterra, respectivamente. 
4.1.2. Nivel de estudios y profesiones. Destaca el alto nivel educativo, mayoritariamente con estudios superiores: 74\%. La profesión que más aparece es la de profesora: de castellano, de violín y viola, de párvulos, de canto, de educación básica, de yoga, de teología y cinco se clasificaron simplemente como profesoras. En cantidad, siguen las empresarias (4) e ingenieras (3) y con dos nominaciones: vendedora, bibliotecaria, psicóloga, secretaria, estilista y misionera (pastora). Finalmente, con una nominación, entre otras: traductora, terapeuta, ecóloga, socióloga, asistente social, kinesióloga, orientadora familiar, química farmacéutica, reflexóloga, enfermera y arquitecta.

4.1.3. Tipo de trabajo. La mayoría, aun cuando tenga una profesión, no desarrollan una actividad remunerada, pues están dedicadas $100 \%$ a la casa y a sus hijos. Un porcentaje menor trabaja de manera independiente y hay un $21 \%$ que desarrollan labores de forma dependiente.

\subsection{Información de los padres}

4.2.1. Edad y procedencia. La cantidad de padres de esta muestra es 64. Hay tres familias que no lo nombran, porque no participa en la crianza y no vive con ellos. El promedio de edad de los padres es de 40 años. Los padres provienen de todo Chile, excepto diez que son originariamente de Argentina (3), Bolivia (2), Ecuador (2) y 1, respectivamente, de México, Estados Unidos y Alemania.

4.2.2. Nivel de estudios y profesiones. Al igual que en el caso de las madres, destaca el alto nivel educativo de los padres: $77 \%$ tiene estudios universitarios. Los tres primeros lugares son ocupados por profesiones como ingeniero (25\%), técnico operador (12\%) y pastor religioso (9\%).

4.2.3. Tipo de trabajo. La mayor cantidad de padres son trabajadores dependientes. En la categoría independiente se agrupó a los padres que declaraban esta condición, además de señalar que tenían oficina propia, que eran empresarios, ingenieros independientes, contador, diseñador gráfico, dueño de local comercial y vendedor de productos naturales.

\section{HaCia Un PRIMER MaPa de La EDUCaCión en el hogar en Chile}

La encuesta pidió la identificación precisa del lugar en que vivían, con el objetivo de establecer una primera aproximación a un mapa de la educación en el hogar en Chile. 
Tabla 1. Cantidad de familias por región geográfica y ciudad

\begin{tabular}{lll}
\hline \multicolumn{1}{c}{ Región } & $\mathbf{N}^{\circ}$ & \multicolumn{1}{c}{ Ciudad } \\
\hline Antofagasta & 04 & 3 Antofagasta, 1 Calama \\
Valparaíso & 10 & 3 Valparaíso, 4 Quilpué, 2 Villa Alemana, 1 Puchuncaví \\
Metropolitana & 33 & 29 Santiago, 1 Puente Alto, 1 La Florida, 1 Isla de Maipo, 1 Buin \\
O'Higgins & 06 & 4 Rancagua, 1 Graneros, 1 Machalí \\
Maule & 01 & Talca \\
Biobío & 09 & 6 Concepción, 2 San Pedro de la Paz, 1 Los Ángeles \\
Araucanía & 02 & 1 Temuco, 1 Angol \\
Los Ríos & 01 & Valdivia \\
Los Lagos & 01 & Puerto Octay \\
\hline
\end{tabular}

Fuente: Datos proporcionados por la encuesta. Elaboración propia.

Una vez categorizado el lugar donde viven y, por lo tanto, dónde realizan la educación en el hogar, se agregó más información al respecto. La gestora del Primer Congreso, Cristina Matus, facilitó una base de datos con 98 encuestas aplicadas entre el 6 de diciembre de 2013 y el 8 de julio de 2014 . Las preguntas no eran las mismas, puesto que su objetivo era averiguar el grado de conocimiento y de participación en actividades de educación en el hogar a diferencia de la encuesta nacional que estaba dirigida específicamente a quienes ya estaban realizando este tipo de educación. Pero la tercera pregunta correspondía a su lugar de residencia y esa era la que nos importaba para el objetivo de establecer un primer mapa de la educación en el hogar en Chile.

El tamizaje de los datos, para lo cual se contrastaron las bases de datos tanto en impresión de papel (utilizando marcadores de colores) como digital, con las herramientas de Excel: Tablas dinámicas y la opción Buscar, arrojó que 47 familias participantes del Primer Congreso no respondieron la encuesta nacional, pero como se consignaba el dato de su lugar de residencia, se podía utilizar esa información para efectos del mapa. 
Tabla 2. Familias por región y ciudad que no participaron en la Encuesta Nacional

\begin{tabular}{lll}
\hline \multicolumn{1}{c}{ Región } & N $^{\circ}$ & Ciudad \\
\hline Coquimbo & 01 & Coquimbo \\
Valparaíso & 09 & $\begin{array}{l}\text { 2 Valparaíso, 1 Viña del Mar, 1 Catemu, 1 Zapallar, 1 Quilpué, } \\
\text { 2 Quillota }\end{array}$ \\
Metropolitana & 33 & 1 La Reina, 1 Colina, 1 Nuñoa, 1 Chicureo, 2 Buin, 27 Santiago \\
Araucanía & 01 & Teodoro Schmidt \\
Los Ríos & 01 & San José de la Mariquina \\
Los Lagos & 02 & Osorno \\
\hline
\end{tabular}

Fuente: Datos proporcionados por la encuesta. Elaboración propia.

Luego, como ejercicio, se agregaron las 36 familias que no participaron del Congreso, pero que ante la pregunta: «Usted se definiría como prácticante de: [...]» eligieron las alternativas «a) Homeschooling, b) Unschooling [sin currículum] y, c) Iniciaré educación en el hogar el próximo año 2015». Esto significaba para este investigador, que ya estaban educando en el hogar, en todo caso fuera del sistema, y los otros manifestaban el compromiso de hacerlo

$\mathrm{Al}$ agruparlas según su lugar de residencia, el resultado fue:

Tabla 3. Familias por región y ciudad que no participaron en el Primer Congreso Nacional

\begin{tabular}{lll}
\hline \multicolumn{1}{c}{ Región } & $\mathbf{N}^{\circ}$ & Ciudad \\
\hline Antofagasta & 01 & Antofagasta \\
Coquimbo & 02 & Coquimbo, La Serena \\
Valparaíso & 07 & $\begin{array}{l}\text { 1 Valparaíso, 1 Viña del Mar, 1 Algarrobo, 1 Concón, 2 Quillota, } \\
\text { 1 Quilpué }\end{array}$ \\
Metropolitana & 18 & 14 Santiago, 1 La Reina, 1 Nuñoa, 1 Maipú, 1 Isla de Maipo \\
O’Higgins & 02 & Palmilla, Graneros \\
Biobío & 01 & Los Ángeles \\
Araucanía & 02 & Angol, Teodoro Schmidt \\
Los Ríos & 03 & 2 Valdivia, 1 Río Bueno \\
\hline
\end{tabular}

Fuente: Datos proporcionados por la encuesta. Elaboración propia. 
Hecha la sumatoria por regiones de Chile, la Figura 1 consigna el mapa tentativo de la educación en el hogar en Chile a junio de 2015, con un total de 150 familias. En las regiones en que no hay guarismo no significa que no existen, significa que es información por levantar.

\section{Figura 1. Familias por región sumados los datos de las dos encuestas}

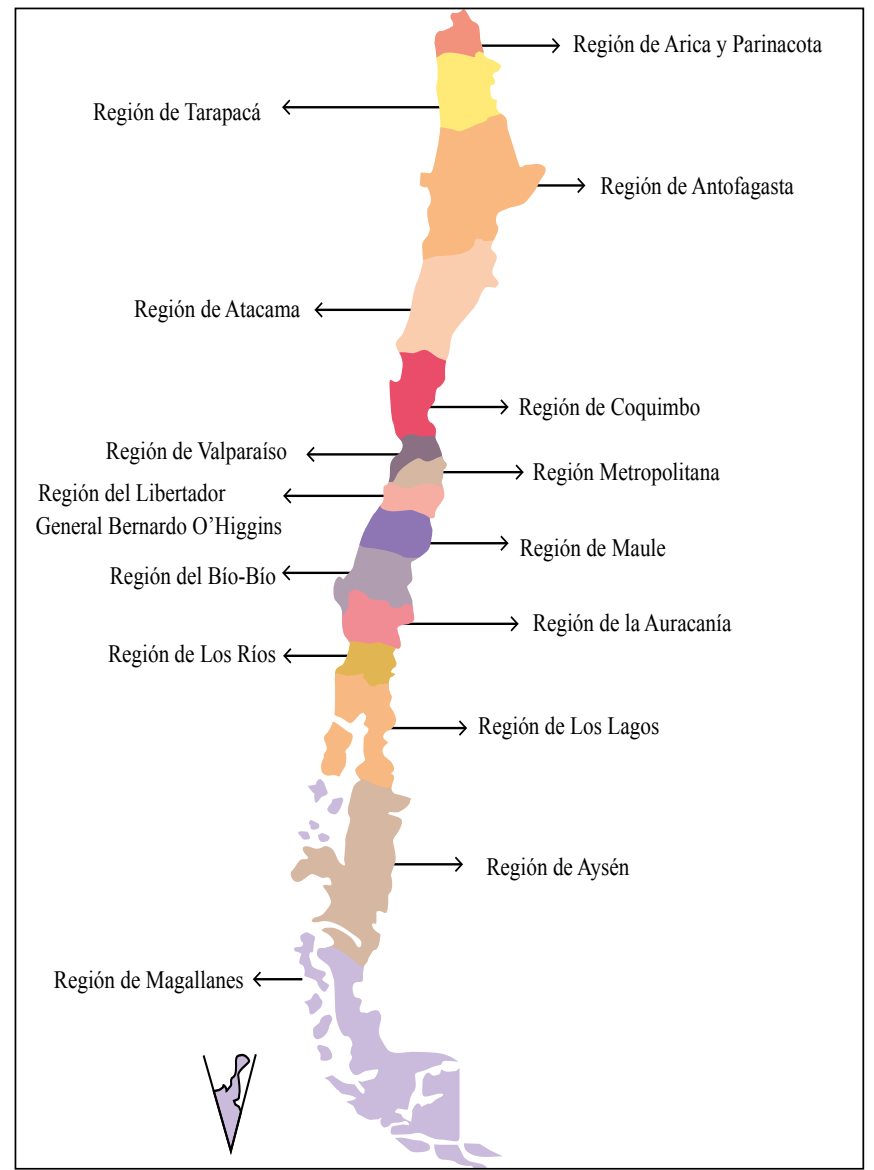

Fuente: Datos proporcionados por la encuesta. Elaboración propia. 


\section{INFORMACIÓN DE LA PAREJA}

6.1. Estado civil y tipo de vivienda. El $70 \%$ corresponde a matrimonios y el $22 \%$ a convivencia. Se trata de familias que en una alta proporción educan en el hogar en ambiente citadino: 52 de 67, es decir, el 78\%. Probablemente la condición de encuesta en línea, que implica cierto nivel de tecnología disponible, tanto en equipo como en red de internet (en Chile hay zonas en que la topografía no permite la conexión), hizo que no se vieran reflejadas en la encuesta algunas familias que conocimos en el Primer Congreso de Homeschooling y que no participaron en este ejercicio. Son familias que hacen educación en el hogar, que viven en zonas rurales y en comunidades: en Caldera, Valle del Elqui, Viña del Mar, Villa Alemana, Pirque, Peñalolén, Melipilla, Cauquenes, Cabrero, Angol (hacia la cordillera de Nahuelbuta), Valdivia, Osorno, Puerto Varas, Chiloé y Magallanes.

\section{Motivos PARA OPTAR POR LA EDUCACIÓN EN EL HOGAR}

7.1. Antecedente. La única referencia conocida hasta ahora es el trabajo de Madalen Goiría, incluido en Goiría (2011) que consiste en un estudio sobre dieciocho encuestas respondidas por familias homeschoolers españolas en 2008. La investigadora utilizó ocho categorías de motivos: religiosos, ideológicos, psicológicos, logísticos, culturales, por conocer a otras familias que lo están haciendo, pedagógicos y lingüísticos.

\subsection{Los motivos en la Encuesta Nacional de Educación en el hogar en}

Chile. De acuerdo con las respuestas, se acotó la categorización de Goiría (2011) a cuatro tipos de motivos: religiosos, ideológicos, psicológicos, y pedagógicos.

Para la gradación se tuvo en cuenta que: en tres casos las familias numeraron los motivos en orden de importancia. En diez casos los motivos estaban separados por guion o asterisco y en los 53 casos restantes se trataba de un solo texto con un motivo general que se explicaba en varios motivos y había que determinar cuál prevalecía.

Los motivos se cuantificaron según criterios de: a) Aparición en el primer lugar de una serie y b) Destacado en un texto amplio.

La tabla 4 sintetiza, agrupándolos de menor a mayor, los motivos que llevan a las familias a educar en el hogar en Chile. 
Tabla 4. Motivos que llevan a educar en el hogar en Chile (de menor a mayor importancia)

\begin{tabular}{lcc}
\hline Motivos & $\mathbf{N}^{\circ}$ & $\mathbf{\%}$ \\
\hline Religiosos & 10 & $15 \%$ \\
Psicológicos & 14 & $21 \%$ \\
Ideológicos & 21 & $31 \%$ \\
Pedagógicos & 22 & $33 \%$ \\
\hline
\end{tabular}

Fuente: Datos proporcionados por la encuesta. Elaboración propia.

\subsection{Análisis de los motivos}

7.3.1. Religiosos. A partir de lo visto y escuchado en el Primer Congreso Nacional de Homeschooling, teníamos la impresión de que este motivo sería de alta prevalencia. Pero en la encuesta recibió la menor inclinación, con 10 menciones en primer lugar, lo que representa un $15 \%$. Nuestra expectativa se basaba en datos proporcionados por la fundadora de la agrupación Homeschool Consagrado al Señor, que en marzo de 2014 recibió 126 formularios electrónicos de inscripción, y por la presencia de diversas denominaciones religiosas en el Congreso: había familias evangélicas, musulmanas, católicas y rastafaris (solo una familia respondió la encuesta) y cuya comunidad visité en una inmersión microetnográfica que originó un artículo que fue publicado por al menos dos medios electrónicos de Chile (El Ciudadano, 2014) y Argentina (Periódico del Bien Común, 2014).

Uno de los nueve padres que respondieron escribió:

Somos una familia cristiana y queremos entregarle los principios cristianos que profesamos, además entendemos que es labor nuestra educarlos, no la escuela. Creemos que deben pasar mayor tiempo con sus padres que con sus iguales, además que se amplía la posibilidad de que ellos se relacionen con diferentes generaciones a la vez. Por último, nos interesamos por una educación integral, enfocada a la realidad de cada uno de nuestros hijos y de una calidad que no se alcanza en la escuela.

7.3.2. Psicológicos. En esta categoría se agruparon las respuestas que tenían que ver con: estrés, acoso, fobias, desmotivación, depresión y felicidad de los niños. Punto aparte es el bullying, que entendemos con Canals (2012) que son comportamientos violentos que persisten en el tiempo. 
Por ejemplo, un matrimonio de extranjeros que trabaja en Chile, ella peruana; él boliviano, pastor evangélico, vive en Valparaíso con sus dos hijos de 12 y 10 años, ambos en educación en el hogar: «Disminuir el estrés de tantas horas de clases en un ambiente con más de 35 alumnos, con jornada completa y además las tareas que llevaban a casa...».

7.3.3. Ideológicos. Aquí se agruparon las respuestas que hacían referencia a una crítica al sistema escolar actual, que en realidad era una crítica al sistema socioeconómico neoliberal. La mayoría de las 21 familias que indicaron en primer lugar motivos ideológicos concordaban con Gardner (2008, p. 23) en que las escuelas sirven «de formas determinadas a determinados propósitos sociales» o consideraba a los sistemas educativos como, al decir de Casassus (2003, p. 31), «instrumentos sociales». También hay indicaciones, en primer lugar, de que la educación es tarea de los padres, que se requiere más libertad, más enseñanza de valores y que la familia necesita un tiempo mayor para compartir.

Fernanda, artista visual de Santiago, que cría a su hija junto a otras familias organizadas en círculos (varios niños compartiendo durante el proceso completo) señaló:

Estamos completamente en desacuerdo con los métodos estatales de pedagogía. La pedagogía tradicional destruye al ser humano como ser integral y lo homogeneiza y lo obliga a ser solo un aparato productivo y obediente [...].

Nosotros usamos el método Waldorf, de hecho hicimos el seminario antroposófico y mediante este enfocamos la pedagogía al servicio del nińo y no el niño al servicio de las materias del colegio [...].

En la educación estatal se intelectualiza al niño desde el jardín de infantes, se menosprecia el arte como herramienta pedagógica y necesidad para el equilibrio del humano $[\ldots]$.

Una de las tres familias que numeraron sus motivos en orden de importancia, empresarios de Buin, escribieron:

1. Para continuar con una crianza respetuosa, que valora los ritmos de los niños, el tiempo para la reflexión, creatividad, compartir en familia, etc.

2. Las largas jornadas en los colegios.

3. Pensamos que el colegio dificulta el aprendizaje más importante para los nińos, la independencia y su desarrollo integral.

7.3.4. Pedagógicos. Muchas familias coincidieron en que lo que se aprende en el sistema escolar es solo una parte de la educación que se necesita y «no siempre la más importante» (García \& Manga, 2013, p. 179). Estos motivos 
fueron los más señalados en orden de importancia. Se indicaban como primer motivo o eran los que prevalecían en un texto extenso. «-Educación más personalizada. -Aprender descubriendo. -Educación integral. -Mayor respeto a la forma de aprender de los nińos. -Discrepar del sistema escolar».

Un matrimonio de ingenieros de Valdivia, ambos de 37 años, con cuatro hijos, señalaron estos motivos para hacer educación en el hogar:

No exponer a mis hijos en los colegios, donde muchas veces los profesores no tienen vocación ni las capacidades y donde además solo se persiguen resultados y desconoce o se pasa por alto los sentimientos, emociones, gustos y habilidades individuales de los nińos.

[...] En el colegio no tienen libertad para jugar, al contrario, pasan la gran parte del tiempo dirigidos por un adulto y luego en la tarde cuando terminan sus actividades están tan agotados que solo llegan a casa a ver televisión o videojuegos y prácticamente nunca tienen mucho espacio para jugar libremente. En esos dos puntos resumo a grandes rasgos el motivo por el cual educamos en el hogar.

Una pareja de Santiago con una hija de 8 años y, que piensan que rendirá exámenes libres en octavo año básico, no antes, respondió:

Sistema educativo anticuado y obsoleto. Horarios escolares excesivos. Desacuerdo con educación basada en la competencia. Deseo de que nuestra hija aprenda jugando y haciendo. Deseo de que tenga libertad para explorar según su interés. Respeto por su ritmo de desarrollo y aprendizaje. Concebimos el aprendizaje como un proceso continuo ligado a la vida real y cotidiana.

\section{Los Valores}

8.1. Los cinco principales valores. La pluralidad de respuestas hizo difícil, mas no imposible, el análisis. Como nos interesa levantar una información que no existe, la pregunta de respuesta abierta era la posibilidad más idónea. La decisión de análisis pasó por determinar cuáles valores aparecían reiteradamente en primer lugar y luego aquellos que se indicaban en primer y segundo lugares.

El valor que tiene más menciones en primer lugar es Amor, con 28 familias que lo nombraron. Amor a secas obtuvo un $42 \%$ de las menciones.

Para una familia de Calama, por ejemplo, la secuencia es (y lo escribió en mayúsculas): «AMOR, COMPRENSION, COMPARTIR MAS COMO FAMILIA, ENTENDIMIENTO, SOLIDARIDAD».

Pamela, que vive con su marido y sus hijos en Concepción, listó no cinco, sino seis valores: «Amor/Responsabilidad/Honestidad/Perseverancia/Lealtad/ Honradez». 
En tanto, amor a Dios, con sus variantes: obediencia, reverencia y valores cristianos presenta 19 primeros lugares con $28 \%$.

De Antofagasta, un matrimonio, ambos de 32 años, indicaron no cinco, sino siete valores: "Amor a Dios por sobret odo/ Amor/ Obediencia/ Respeto/ Honestidad/ Esfuerzo/ Excelencia».

Un matrimonio de profesionales, ella fonoaudióloga, él ingeniero, que viven en Valparaíso, hacen educación en el hogar con su hija de tres años. Acerca de los valores, escribieron: "Amor y temor a Dios/Respeto mutuo/ Sinceridad/Paciencia/Dominio propio».

El otro valor que más aparece en primer lugar es respeto, con 11 menciones, lo que equivale al $16 \%$. Una madre profesora de violín y viola educa a su hija de 13 años con estos valores: «Respeto al proceso individual de aprendizaje/ autodisciplina/solidaridad/amor por el estudio y los libros/ser curioso, buscar aprender más allá de temarios y obligaciones».

Una familia que vive en Los Ángeles, en una casa en parcela o campo, con dos hijas, declaró los valores que inspiran su trabajo como educadores en el hogar: «Respeto/tolerancia/paciencia/trabajo en equipo/optimismo».

Otras ideas que aparecieron en primer lugar fueron: felicidad y unidad familiar (dos menciones). Con una mención: seguridad, voluntad, conocer cosas nuevas, tranquilidad del niño y compartir aprendizajes.

En la tabla 5 se presenta un resumen de los valores que aparecen en primer lugar.

Tabla 5. Valores que llevan a educar en el hogar en Chile (de mayor a menor importancia)

\begin{tabular}{lcc}
\hline Valor & $\mathbf{N}^{\circ}$ & $\mathbf{\%}$ \\
\hline Amor (a secas) & 28 & 42 \\
Amor a Dios & 19 & 28 \\
Respeto & 11 & 16 \\
Otros & 9 & 13 \\
\hline
\end{tabular}

Fuente: Datos proporcionados por la encuesta. Elaboración propia.

El valor más relevante para las familias que educan en el hogar es el amor, tanto en general (42\%) como a Dios en particular (28\%). Es significativo que si se reducen estos datos a una sola categoría se llega al 70\% de importancia del amor como valor principal que inspira el trabajo de las familias que educan en el hogar en Chile. 


\section{VALIDACIÓN DE ESTUdios POR EXÁMENES LIBRES}

De las 67 familias encuestadas, 22 han pasado por la experiencia de presentar a sus hijos/as, (36 en total), a exámenes libres. En tanto, 97 niños/as de las 45 familias restantes no han rendido exámenes de validación de estudios.

La encuesta consultaba a quienes informaban que sus hijos/as no habían rendido exámenes libres por qué no lo habían hecho, con respuesta abierta. El análisis de los 97 casos que no se han examinado permitió establecer las siguientes razones y su concreción en números:

Porque es el primer año de educación en el hogar: 43 niños/as, 44\%. No le corresponde por edad: 15 niños/as menores están recibiendo educación en el hogar.

Se examinarán en $4^{\circ}$ u $8^{\circ}$ básico: 14 niños/as rendirán exámenes libres al terminar al primer ciclo de enseñanza básica, $4^{\circ}$ año, o el segundo, $8^{\circ}$ básico. Rendirá a fin de año. 10 familias señalan que los hijos/as a quienes les corresponde por edad, se examinarán al final del año corriente.

No creen necesarios los exámenes: 6 familias.

No responden: 6.

Los 36 niños/as que han rendido exámenes libres han tenido buen o muy buen rendimiento. De hecho, entre 5,0 (bueno) y 7,0 (muy bueno) se agrupa casi el 90\%. No hay evaluados negativamente.

De las 67 familias encuestadas, 10 manifestaron haber tenido algún problema con la examinación. En 8 casos, el problema fue el desconocimiento del tema por parte de los funcionarios.

\section{Fuentes PARA El CURRÍCULUM}

El qué y cómo enseñar, siguiendo a Gvirtz y Palamidessi (2012) no presentó problemas en las respuestas. Redactamos la pregunta de manera que la entendieran las personas que no tenían nociones técnicas sobre el tema.

La redacción fue:

¿Qué fuentes utilizan para el tema de las materias, el currículum, que deben desarrollar sus hijos/as, según el año que estén cursando? (currículum en línea del Mineduc, libros de texto del año respectivo, asesoría de docentes, colegios en línea o no siguen un programa específico).

Las respuestas fueron categorizadas en tres grupos: 
1. Currículum en línea y libros de texto del Ministerio de Educación: 48 familias.

2. No siguen un programa específico, sino que construyen su propio programa: 13.

3. Siguen otro sistema (colegio virtual, método Kumon, Waldorf): 6.

\section{Socialización}

Este es uno de los temas que más llama la atención en la educación en el hogar. Y lo hace desde un punto de vista negativo, porque muchas personas, por el paradigma de la escuela, sostienen que en un curso con treinta o cuarenta compañeros es donde se sociabiliza mejor. Las familias que educan en el hogar tienen una visión y una práctica distintas.

Como las respuestas eran abiertas y muy diversas, se desarrolló el siguiente procedimiento.

1. Primera lectura. Lectura completa para tener una primera aproximación. Ya empiezan a aparecer palabras que se repiten: iglesia, talleres, deportes, música, ballet.

2. Segunda lectura. Lectura completa y se marca con asteriscos y/o tiques algunas respuestas que llaman la atención por ser reiteradas, representativas, bien redactadas o porque desarrollan un punto interesante o importante

3. Tercera lectura. Lectura completa y se marca con destacador la palabra «iglesia», se chequea con la opción Buscar del programa Excel y se concuerda que son 18. Pero en una revisión más exhaustiva se descubren expresiones como: "Asistimos tres veces por semana a una asamblea cristiana donde los niños socializan con adultos y otros niños de su edad, aprenden a comportarse en público y respetan a sus semejantes y a sus mayores...».

4. Finalmente, en una cuarta lectura de chequeo se determina que son 24 las referencias a actividades sociabilizadoras que tienen que ver con la iglesia a la que concurren, entre otras acciones que desarrollan para trabajar el aspecto consultado.

5. Vuelvo a revisar si hay respuestas que pudiera destacar y cruzo con el nombre de pila de quien responde y la ciudad donde vive. Me parece que al citarlos con nombre y ciudad puedo atribuirle alguna imagen mental a las frías palabras, sin caer en traicionar el anonimato y también que se puede apreciar la variedad geográfica de las familias que hacen educación en el hogar.

6. Cuando hago un arqueo de las respuestas/nombres/ciudades me doy cuenta que quisiera mostrar todavía más variedad geográfica, así que busco 
zonas no representadas y me percato que solo hay cuatro representantes del norte de Chile: tres de Antofagasta y uno de Calama.

Las actividades que más se nombraron fueron las relacionadas con clases o talleres de desarrollo de habilidades deportivas y artísticas.

Las familias fueron muy explícitas para resaltar que justamente uno de los puntos altos de la educación en el hogar es precisamente el desarrollo de un excelente nivel de sociabilidad.

Joana, del Entorno Educador Kume Monguén de Concepción, respondió:

¡Lucho para tener a mi hijo en casa un rato porque es demasiado social (nunca ha ido al colegio). Los niños educados en casa no aprenden a sobrevivir en un grupo/manada de 40 niños de su edad. Aprenden a jugar con chiquitos y grandes, bebés y abuelitos, sin los prejuicios inevitables en el sistema escolar. Aprenden a conversar con ricos y pobres, con el panadero y el doctor, sin actitud sumisa ni desafiante, porque es algo que han hecho todos los días de forma natural.

\section{Participación en grupos}

Se consultó a las familias si participaban en alguno de los varios grupos de educación en el hogar o homeschooling que existen en el país. El 79 \%, dijo que sí y nombraron los siguientes sitios:

En Facebook: Educando en el Hogar Chile que cambió en 2014 a Educar en Libertad. Unschooling Chile; Homeschool Consagrado al Señor; Biblioteca para Madres y Padres Educadores en el Hogar; Homeschool Chile; Escuela Kume Monguén; Educación Waldorf en el Hogar; Colegio en casa (Valdivia); La escuelita - Valdivia; Educación en el Hogar Concepción; Homeschool Antofagasta, Madres Maestras; Compartiendo el homeschooling - Chile; Familia que enseña, Educar en el Hogar.

En Blogspot.com: KomUnidad Educativa Wenuleufu (Valdivia); Homeschool Consagrado al Señor (Santiago); Centro Cultural Kume Monguén (Concepción)

\section{TIEMPO DEDICADO A LA EDUCACIÓN EN EL HOGAR}

La mayoría de las familias respondieron que hacían educación en el hogar todo el ańo, 14 señalaron de marzo a diciembre, 11 de marzo a noviembre y 11 en meses diversos o no lo tenían claro. De las 67 familias encuestadas, 37 declararon destinar 5 días a la educación en el hogar, lunes a viernes, 11 todos los días, 11 no lo indican y las 8 restantes en días diversos. 
Finalmente, el horario más utilizado, 44\%, es en las mañanas de 8 a $13 \mathrm{~h}$. Le sigue el horario de 9 a 18 h, con $18 \%$ y a toda hora el $15 \%$. El 22\% restante se distribuye en horarios diversos o no lo indicaron.

\section{Discusión de RESUltados y CONCLUSIONES}

En el análisis de los datos encontramos algunas coincidencias interesantes: Entre 30 y 49 ańos (90\%), es la edad que más aparece al revisar en detalle la edad de las madres y padres que educan en el hogar en Chile. Esto nos permite indicar que son personas adultas, de una edad mayor, que hace suponer una madurez o conocimiento del mundo más amplio que los padres jóvenes y que su decisión de desescolarizar a sus hijos/as no es un arrebato o acción que esté guiada por circunstancias del momento. Esto queda claro, además, al ver las razones que expresan, especialmente en el ámbito de los motivos y valores.

Otra regularidad de la muestra es que tanto las madres como los padres son mayoritariamente de la región metropolitana, donde se ubica la capital de Chile: Santiago.

También se aprecia homogeneidad en los datos de la muestra en lo referente a los estudios de las madres y padres: Si 53 padres tienen estudios superiores, las madres son 52. Si son 8 los padres que tienen estudios de nivel técnico, las madres son 7 . Y si son 6 los padres que tienen solo enseñanza secundaria completa, las madres son 8 .

Finalmente, la muestra indica que son 133 los hijos/as que viven la educación en el hogar, de los cuales 66 son damas y 67 son varones.

En las profesiones y tipos de trabajo se aprecian grandes diferencias: el $35 \%$ de las madres son profesoras o dueñas de casa y el 37\% de los padres son ingenieros o técnicos. Con respecto al tipo de trabajo es homogéneo el resultado numérico en los dos primeros tipos: En la casa y dependiente (madres: 81\%; padres: $83 \%$ ) con la diferencia que en el caso de las madres «en la casa» es no remunerado. En los padres, corresponde al tipo de trabajo denominado «home office», generalmente bien remunerado.

Uno de los mitos que se escucha o lee acerca del homeschool es que lo practican familias adineradas o "alternativas», fuera del sistema, que suelen vivir alejadas de las grandes ciudades o centros de poder. $\mathrm{Al}$ menos en este primer ejercicio para establecer la ubicación en general de las familias que practican la educación en el hogar en Chile, la mayor cantidad la encontramos en el centro del país, en las regiones: Metropolitana, de Valparaíso y del Biobío, en ese orden.

Otro mito cuestionado por los datos de esta encuesta es que muchas personas piensan que las familias deciden educar en el hogar por motivos reli- 
giosos o sicológicos (desadaptación a la escuela, bullying, etc.). Esta encuesta encontró que los motivos que más inciden a la hora de tomar la decisión de educar en familia son los motivos pedagógicos e ideológicos, con 33\% y $31 \%$ respectivamente, sumando un total de 43 familias en las 67 de la muestra. Curiosamente, el motivo menos seńalado por los padres es el religioso, que llega solo al 15\%. Este dato debiera ponerse en discusión en una investigación posterior, porque la experiencia nos indica que el factor religioso es más importante de lo que aparece aquí y que muchas familias cristianas protestantes prefieren el trabajo discreto al interior de sus propias comunidades. A comienzos de 2015 este investigador asistió en Santiago, comuna de Maipú, a un encuentro de la agrupación Homeschool Consagrado al Señor y en esa actividad había más de 40 familias representantes de otras agrupaciones cristianas.

En términos de los valores que llevan a educar en el hogar en Chile, consecuentemente, el amor a Dios no fue el valor más apuntado. Sí fue el amor, pero a secas y sin considerar que el tercer valor más señalado fue respeto, que es otra forma de dar amor, lo que llevaría a un $85 \%$ la importancia del amor como valor relevante a la hora de decidirse por la educación en casa.

De los 133 niños/as de esta muestra, solamente 36 se han inscrito y rendido exámenes libres. Se aprecia, de todas maneras, que muchas familias estaban en su primer año de educación en el hogar y esto podría augurar que en años venideros la cantidad de examinados por libre será mayor.

Lo que nos pareció notable fue la evaluación obtenida en general por los niños y niñas que rinden exámenes libres. Habíamos escuchado y leído comentarios en Facebook acerca de lo bien que les iba en la evaluación. Las cifras señalan que todos aprueban y que el $86 \%$ lo hace con calificaciones situadas en las categorías de Bien $(5,0)$ a Muy bien $(7,0)$.

En un hecho que se considera grave, destaca un $15 \%$ de familias que declaran haber tenido problemas al solicitar la evaluación libre, que está contemplada en la normativa ministerial. Diez familias declaran haber tenido dificultades, principalmente por desconocimiento del tema por parte de funcionarios de las Direcciones Provinciales de Educación donde debe concurrir quien desea o necesita rendir exámenes libres, inscribirse y recibir posteriormente la indicación del colegio o escuela designados para la evaluación.

Se consignan muchas fuentes para apoyar la educación en el hogar, principalmente de sitios del Ministerio de Educación (lo que es un contrasentido si se le critica tanto) y de los textos de estudio que el referido Ministerio entrega a cada escolar matriculado en el sistema y afecto a subvención estatal, es decir, de colegios municipalizados y particulares subvencionados. 
La falta de sociabilización, que siempre es esgrimida por quienes se oponen a la educación en el hogar, no es un problema. Muy por el contrario. En la encuesta, las familias indican múltiples oportunidades de sociabilización que los padres, en familia o grupos, le brindan a sus hijos/as. Este es otro mito cuestionado por los datos de la encuesta: al contrario de lo que se piensa, los niños educados en el hogar muestran mejores capacidades y habilidades para relacionarse con otras personas, porque no tienen algunas estructuras de respuesta (paradigmas) que enseña la escuela en el ámbito, por ejemplo, del respeto a la autoridad y de los límites en la relación entre pares y entre "grandes y chicos» y de lo que un niño/a puede y/o debe saber a ciertas edades.

La participación en grupos igualmente cuestionó una mirada que se tiene con respecto a que la educación en el hogar en Chile no sería lo que es, si las familias no se apoyaran tanto, especialmente a través de las redes sociales. Hay una mayoría que lo hace y en este trabajo se consignan todos los indicados por las familias. Por eso se esperaba una participación mayor en la encuesta. No obstante, el $21 \%$ señaló no participar en estos grupos.

Finalmente, el tiempo destinado a la educación en el hogar, medido en meses del año es en general bastante similar al año lectivo oficial. La diferencia está en el horario que siempre es menos que las aproximadamente ocho horas pedagógicas en las escuelas y colegios del país, excepción hecha de varios que dijeron que todo horario es educador, si la ocasión lo permite o requiere.

Como se ve, los resultados de esta encuesta permiten hacerse una primera idea acerca del fenómeno del homeschooling en Chile o educación en el hogar como preferimos llamarlo, apelando a los significados de «educación» como proceso permanente de formación y «en el hogar» como el espacio amoroso mejor preparado para sembrar y lograr aprendizajes significativos, sin temores y sin restricciones inexplicables a esta altura de los tiempos, como la disciplina rígida, la permanente evaluación cuantitativa y competitiva, los uniformes, las salas de clases como único espacio para aprender, la entrada a la misma hora cada día y el trabajo académico dispuesto desde la autoridad ministerial o docente.

Este trabajo se propone como base para otros que actualicen, contradigan y hagan más luz acerca de la educación en el hogar en Chile.

\section{REFERENCIAS BIBLIOGRÁFICAS}

Aliaga, L. (2013). Cuarenta ańos después ¿La escuela ha muerto? Revista Iberoamericana de Estudios en Educación, 8(1). Recuperado el 31 de octubre de 2015 de http://seer.fclar.unesp.br/iberoamericana/article/view/6477 Canals, S. (2012). Si todo es bullying nada es bullying. Santiago: Uqbar Editores. 
Casassus, J. (2003). La escuela y la (des)igualdad. Santiago: LOM Ediciones.

Céspedes, A. (2014). 100 preguntas sobre educación escolar. Santiago: Ediciones B Chile S. A.

Constitución Política de Chile (2012). Capítulo III: De los derechos y deberes constitucionales. Recuperado el 01 de noviembre de 2015 de http:// www.senado.cl/capitulo-iii-de-los-derechos-y-deberes-constitucionales/ prontus_se-nado/2012-01-16/093413.html

Escriu, J. (2015). Nosotros, los homeschoolers. Realidades, mitos y leyendas. Barcelona: Amazon.

Fraser Institute (2015). Home Schooling in Canada: The Current Picture - 2015 Edition.Recuperadoel 16dediciembrede2015dehttp://www.fraserinstitute. org/research/home-schooling-canada-current-picture\%E-2\%80\%942015

García, J. \& Manga, M. (2013). Inteligencia Relacional. Santiago: Ediciones B Chile S.A.

Gardner, H. (2008). La mente no escolarizada. Buenos Aires: Paidós.

Goiría, M. (2011). Un análisis de las encuestas realizadas a familias que educan sin escuela. En Erwin Fabián García López (comp.), Un mundo por aprender. Educación sin escuela (ESE), Autoaprendizaje Colaborativo (AC) y Educación en Familia (EF): Artículos de Congresos 2009 y 2010. Bogotá: Universidad Nacional de Colombia, Facultad de Ciencias Humanas.

El Ciudadano (2014, abril 23). Quiénes son y cómo educan los rastafari de Villa Alemana. Recuperado el 20 de noviembre de 2015 de http:// www.elciudadano.cl/2014/04/23/104608/quienes-son-y-comoeducan-los-rastafari-de-villa-alemana/

Gvirtz, S. \& Palamidessi, M. (2012). El abc de la tarea docente: currículum y enseñanza. Buenos Aires: Aique Grupo Editor.

Lagos, J. (2012). Derechos de educación de los padres en Canadá: Canon y Derecho Civil. Enfoques de educación en el hogar. Studia Canónica, 46, 401-469.

Murphy, Joseph (2012). Homeschooling in America: Capturing and Assessing the Movement. Thousand Oaks, CA: Corwin.

Periódico del Bien Común (2014, febrero). Los rastafari de Villa Alemana. Cómo son, cómo educan. Recuperado el 01 de noviembre de 2015 de http://www.periodicodelbiencomun.com/novedades/los-rastafari-de-villaalemana-chile-quienes-son-como-educan/

Universia-Argentina (2015, abril 6). Homeschooling: llevar la escuela a la casa. Recuperado el 01 de noviembre de 2015 de http://noticias.universia. com.ar/educacion/noticia/2015/04/06/1122634/homeschooling-llevarescuela-casa.html 